\title{
Advection patterns and aerosol optical and microphysical properties by AERONET over south-east Italy in the central Mediterranean
}

\author{
M. Santese, F. De Tomasi, and M. R. Perrone \\ CNISM, Physics Department, University of Salento, Via per Arnesano, 73100, Lecce, Italy \\ Received: 4 September 2007 - Published in Atmos. Chem. Phys. Discuss.: 15 November 2007 \\ Revised: 31 January 2008 - Accepted: 15 February 2008 - Published: 31 March 2008
}

\begin{abstract}
Aerosol products by AERONET sun-sky radiometer measurements combined with air-mass backtrajectories were analyzed to identify source regions and pathways of air masses carrying aerosols to south-east Italy, and to determine the dependence of aerosol mean optical properties on advection patterns. Aerosol optical depth (AOD), fine mode fraction $(\eta)$, single scattering albedo (SSA), asymmetry factor $(g)$, and lidar ratio $(L r)$ at $440 \mathrm{~nm}$ were used to characterize aerosol properties. The analysis of 5-day-backtrajectories ending in Lecce on south-east Italy and referring to 240 measurement days of the 2003-2004 years revealed that 32\% of the measurement days were characterized by air masses coming from all continental European sources with the exception of Spain. 3\% of the measurement days were characterized by air masses coming from both the Southern Mediterranean Sea and the Africa continent, and the Western Mediterranean, the Iberian Peninsula, and the Atlantic Ocean. $62 \%$ of the measurement days were characterized by mixed advection patterns. We found that AOD, SSA and $g$ average values were not significantly dependent on air mass source regions. In contrast, $\eta$ and $L r$ average values were quite affected by the air mass source region. AOD, $\eta$, SSA, $g$, and $L r$ average values, which were equal to $0.29 \pm 0.15$, $0.93 \pm 0.03,0.93 \pm 0.03,0.67 \pm 0.03$, and $72 \pm 20 \mathrm{sr}$, respectively indicated that the aerosol advected from all continental European sources with the exception of Spain, could be considered representative of "continental average aerosol", mostly made of water soluble and a small amount of soot and insoluble components. Polluted-desert dust particles characterized by AOD $=0.29 \pm 0.05, \eta=0.72 \pm 0.05$, $\mathrm{SSA}=0.94 \pm 0.03, g=0.69 \pm 0.02, \quad L r=56 \pm 13 \mathrm{sr}$, were advected over south-east Italy from the Southern Mediterranean Sea and the Africa continent. The Western Mediterranean,
\end{abstract}

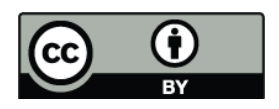

Correspondence to: M. Santese (monica.santese@le.infn.it) the Iberian Peninsula, and the Atlantic Ocean were instead responsible of the advection of maritime-polluted particles, which were characterized by AOD $=0.27 \pm 0.17, \eta=0.8 \pm 0.1$, $\mathrm{SSA}=0.94 \pm 0.03, g=0.67 \pm 0.03, L r=58 \pm 24$ sr. Hence, we found that the aerosol load over south-east Italy was dominated by moderately-absorbing, fine-mode particles even if it was also affected by the minor contribution of desert and maritime type aerosol. The application of an aerosol mask to the data points retrieved on measurement days characterized by mixed advection patterns, supported last comment

\section{Introduction}

Aerosol effects on climate are quite dependent on aerosol optical and microphysical properties (e.g. Giorgi and Bi, 2002; Horvath et al., 2002; Meloni et al., 2005). Thus, the characterization of aerosol properties is crucial to understand their influence on the Earth-atmosphere radiation budget. The Mediterranean region is certainly one of the most interesting regions in terms of atmospheric particulate and various model studies predicted maximum net direct radiative forcing by aerosols for this region (e.g. Charlson et al., 1991; Hatzianastassiou et al., 2004; Giorgi, 2006). The Mediterranean Sea that is bounded to the north by the European continent and to the south by North Africa, is largely affected by different types of particles: desert dust, from the Sahara desert and surrounding arid regions; anthropogenic particles, produced mainly in urban and industrial areas of Europe; marine aerosol, from the Mediterranean itself or transported from the North Atlantic; and biomass burning particles, often produced in forest fires (e.g. Lelieveld et al., 2002; Barnaba et al., 2004; Pace et al., 2006; Barnaba et al., 2007). The strength of dust outbreaks over the Mediterranean tends to facilitate the Saharan dust detection by both ground and space based observations, allowing the quantification of its transport and optical and microphysical properties (e.g. De

Published by Copernicus Publications on behalf of the European Geosciences Union. 
Tomasi et al., 2003; Tafuro et al., 2006). In contrast, the export of particulate matter from the industrialized countries surrounding the Mediterranean is complicated by the fact that an extremely large number of species and gas precursors contribute to it (e.g. Formenti et al., 2002; Barnaba et al., 2004). The Mediterranean Intensive Oxidant Study (MINOS) Project that highlighted the important role of pollutants in the summertime Mediterranean atmosphere is representative of the international effort to quantify the impact of anthropogenic emissions on the natural background of the Mediterranean environment (Lelieveld et al., 2002). Barnaba and Gobbi (2004), for the sole Mediterranean basin and for the whole 2001, implemented a method (aerosol mask) to separate, on the basis of MODIS data, the contribution to the total aerosol optical depth (AOD) of the three aerosol types prevailing over the Mediterranean basin: maritime, continental and desert dust aerosol. In the paper of Barnaba and Gobbi (2004) the application of an aerosol mask showed that in urban/industrial conditions, optical properties are dominated by fine particles while, in the presence of desert dust, these are strongly dominated by coarse particles. In maritime conditions, the relative contribution of coarse particles, although variable, is generally higher than in urban/industrial conditions and lower than for desert dust. Models were also usefully employed to investigate the export pathways of air pollution from Europe (Stohl et al., 2002; Duncan and Bey, 2004). The cluster analysis that appeared at the end of the 80's (Kalkestein et al., 1987; Moody, 1986; Moody and Galloway, 1988) represents a valuable tool to reduce the subjectivity of the atmospheric aerosol classification. Four-day back trajectories categorized in five major clusters were used by Kazadzis et al. (2007) to assess the influence of long-range transport from various regions to the aerosol load over Thessaloniki (Greece). The cluster analysis showed that the contribution of air masses coming from the North and North Eastern directions resulted in high aerosol loads over Thessaloniki, while minimum aerosol optical depth was associated with air masses originating from the Atlantic ocean. Five-day backtrajectories were used by Pace et al. (2006) to characterize at Lampedusa (Central Mediterranean) aerosol optical properties retrieved from multi filter rotating shadowband radiometer (MFRSR) observations (July 2001-September 2003). The backtrajectory analysis revealed that in cloud-free conditions, $36 \%$ of the air masses come from Africa, 25\% from Central-Eastern Europe, and 19\% from Western France, Spain and the North Atlantic. In almost all cases, African aerosols display high values of AOD and low values of Angstrom exponent $\AA$ (average values of AOD and $\AA$ are 0.36 and 0.42 , respectively). Particles originating from Central-Eastern Europe show relatively large average values of AOD and $\AA(0.23$ and 1.5, respectively), while particles from Western France, Spain and the North Atlantic show the lowest average values of AOD (0.15), and relatively small values of $\AA$ (0.92). Four-day backtrajectories were used by Fotiadi et al. (2006) to characterize the aerosol physical and optical properties over the eastern Mediterranean basin using a complete series of two-year (2003-2004) measurements from the FORTHAERONET station in Crete. The broad frequency distributions of AOD and $\AA$ values together with the backtrajectory analysis revealed the presence of a great variety of aerosol types over the study region including dust, urbanindustrial and biomass-burning pollution, and maritime, as well as mixed aerosol type. Several experimental studies on aerosols were focused on the Eastern Mediterranean area in the last decade (Mihalopolulos et al., 1997; Papayannis et al., 1998, 2005; Formenti et al., 2001, 2002; Lelieveld et al., 2002; Gerasopoulos et al., 2003; Balis et al., 2003, 2004; Amiridis et al., 2005). In contrast, only few studies were conducted to characterize aerosol properties in the Central Mediterranean.

In this work, aerosol measurements from the AERONET station in Lecce $\left(40^{\circ} 20^{\prime} \mathrm{N}, 18^{\circ} 06^{\prime} \mathrm{E}\right)$ combined with five-day backtrajectories were analyzed to characterize aerosol properties over the Central Mediterranean basin, to assess the impact on the aerosol load of long-range transport from various regions, and to study the mixing of different aerosol types. The aerosol data include AOD, single scattering albedo (SSA), asymmetry factor $(g)$, Angstrom coefficient $(\AA)$, fine-mode fraction $(\eta)$, and lidar ratio $(L r)$ retrieved from measurements performed in the period March 2003October 2004. The location of the Lecce-AERONET station offers a good opportunity to monitor aerosols from different sources and distinguish among various aerosol load scenarios, being on a narrow peninsula of south-east Italy away from large cities and industrial areas, $\sim 20 \mathrm{~km}$ away from both the Ionian and the Adriatic Sea, $\sim 100 \mathrm{~km}$ away from the western Balkan peninsula coast, and $\sim 800 \mathrm{~km}$ away from the North Africa coast. Satellite images and data from the MODerate resolution Imaging Spectroradiometer (MODIS) were also used to better assess the effects of forestfires (http://maps.geog.umd.edu/firms/) and dust outbreaks (http://modis.gsfc.nasa.gov) on aerosol properties.

A brief description of AERONET instrumentation and retrievals, and backtrajectory data is given in Sect. 2. The methodology used to select main advection patterns over the monitoring site by the 5-day backtrajectories analysis is illustrated in Sect. 3. Section 4 provides a general description of the aerosol properties over the AERONET monitoring station. The dependence of aerosol properties on advection patterns is illustrated in Sect. 5. Summary and conclusion are given in Sect. 6.

\section{AERONET instrumentation and retrievals and back- trajectory properties}

AERONET is a federated international network of sun/sky radiometers established in 1993 that maintains more than 400 instruments worldwide (Holben et al., 1998, 2001). 
Data are publicly available online in near real-time mode (http://aeronet.gsfc.nasa.gov). Aerosol parameters presented in this study were retrieved by measurements with the AERONET sun/sky radiometer operating since March 2003 at Lecce, on the roof of the Physics Department of Universita' del Salento $\left(40.33^{\circ} \mathrm{N}, 18.10^{\circ} \mathrm{E}, 27 \mathrm{~m}\right.$ a.s.l.). The CIMEL sun/sky radiometer measures direct sun radiance in eight spectral channels between 340 and $1020 \mathrm{~nm}$ (340, 380, 440,500, 670, 870, 940 and $1020 \mathrm{~nm}$ ). Sky measurements are performed at 440,670, 870 and $1020 \mathrm{~nm}$ wavelengths through a wide range of scattering angles from the Sun (Holben et al., 1998). An automated cloud-screening algorithm (Smirnov et al., 2000) is applied to AOD direct-sun measurements. Aerosol microphysical parameters are retrieved from direct sun and diffuse sky radiance measurements by a flexible inversion algorithm, developed by Dubovik and King (2000). A discussion on the accuracy of individual retrievals is reported in Dubovik et al. $(2000,2002)$. In particular, the AOD accuracy is of \pm 0.01 in the range $440-1020 \mathrm{~nm}$, while the accuracy of SSA and $g$ at $440 \mathrm{~nm}$ is \pm 0.03 and \pm 0.02 , respectively. Quality assured (automatically cloud cleared and manually inspected) level 2 AERONET data from the V1 algorithm (Smirnov et al., 2000) and retrieved from measurements performed between March 2003 and October 2004, were used in this study. It is worth mentioning that daily averaged products of level 1.5 AERONET data retrieved from measurements performed between March 2003 and March 2004, were analyzed by Perrone et al. (2005) to investigate the seasonal dependence of aerosol properties over south-east Italy.

In our study, 5-day analytical backtrajectories were used to characterize main advection patterns over the Lecce AERONET site. Analytical backtrajectories provide information on the aerosol origin observed at a particular location and on the dynamical patterns governing the air mass transport (Kazadzis et al., 2007). The used backtrajectories are based on the trajectory Code 613.3 developed at NASA/Goddard - The Atmospheric Chemistry and Dynamics Branch (http://croc.gsfc.nasa.gov/aeronet/index. $\mathrm{html}$ ) and are provided for distinct arrival pressure levels and for two arrival times (12:00 and 24:00 UTC) on a day-by-day basis. The backtrajectories of all measurement days within March 2003-October 2004, for the arrival time of 12:00 UTC and for arrival pressure levels of $950,850,700$, and $500 \mathrm{hPa}$ were used in this study. Lidar measurements at Lecce revealed that the aerosol load extends up to $\sim 5 \mathrm{~km}$ from ground (De Tomasi et al., 2006) and as a consequence, backtrajectories having arrival pressure levels higher than $500 \mathrm{hPa}$ have not been taken into account.

In addition to 5-day analytical backtrajectories, MODIS images by Terra and Aqua satellites (http://rapidfire.sci.gsfc. nasa.gov/realtime/2008029/) and MODIS fire maps (http: //maps.geog.umd.edu/firms/) were also used to infer the advection of dust and biomass burning particles, respectively over south-east Italy.

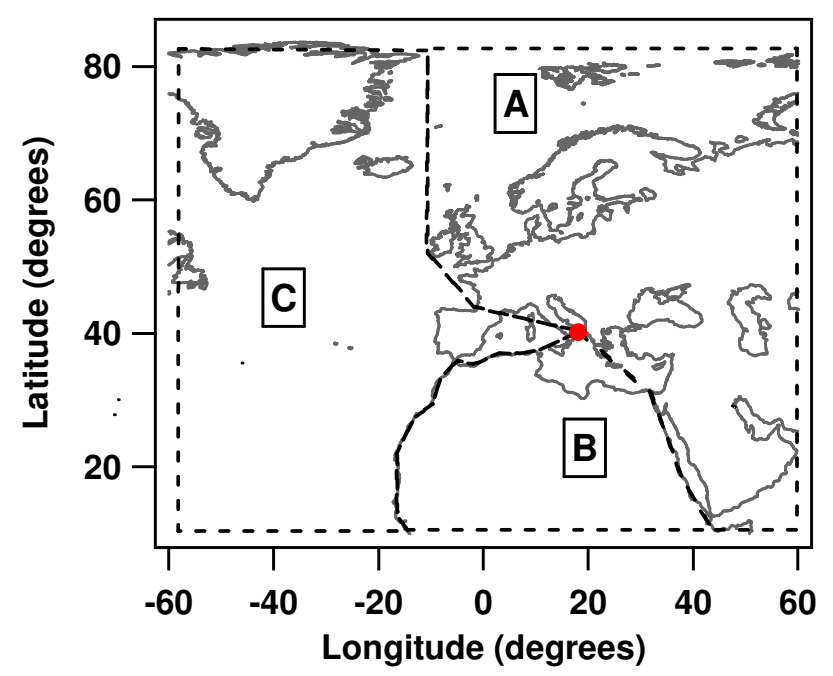

Fig. 1. Aerosol source Sectors: Sector A, includes all continental European sources with exception of Spain, Sector B, includes the Southern Mediterranean Sea and the Africa continent, and Sector $\mathrm{C}$, includes the Western Mediterranean, the Iberian Peninsula, and the Atlantic Ocean.

\section{Aerosol source regions by 5-day backtrajectories}

Considering main advection patterns over south-east Italy (Perrone et al., 2005; De Tomasi et al., 2006), three broad geographical sectors, shown in Fig. 1, were defined as aerosol source regions: Sector A, which includes all continental European sources with the exception of Spain that is generally crossed by air masses from the west Atlantic Ocean; Sector B, which includes the Southern Mediterranean Sea and the Africa continent; Sector C, which includes the Western Mediterranean, the Iberian Peninsula, and the Atlantic Ocean. Air masses from Sector A have the common property to travel across several industrialized European areas before reaching Lecce (De Tomasi et al., 2003). African deserts are instead the main sources of the Sector B aerosol. Marine and to lesser extent anthropogenic particles from the Atlantic Ocean (http://www.esrl.noaa.gov/csd/ICARTT/) and/or the Western Mediterranean regions are expected to be advected from Sector C.

The time spent by the trajectories in a Sector up to the measurement day was also considered to better define the aerosol origin sector. In particular, we assumed that Sector $\mathrm{A}$ is the aerosol source region if at least three of the four back trajectories having 950,850, 700, and $500 \mathrm{hPa}$ arrival pressure level, respectively, spent at least $80 \%$ of the time within the Sector before reaching the sampling site. Africa deserts were considered responsible of the advection of particles over southern-eastern Italy if at least two of the four back trajectories used in this study, spent more than $10 \%$ of time inside the border of the African continent and more than $60 \%$ of the time inside the Sector B before getting to 

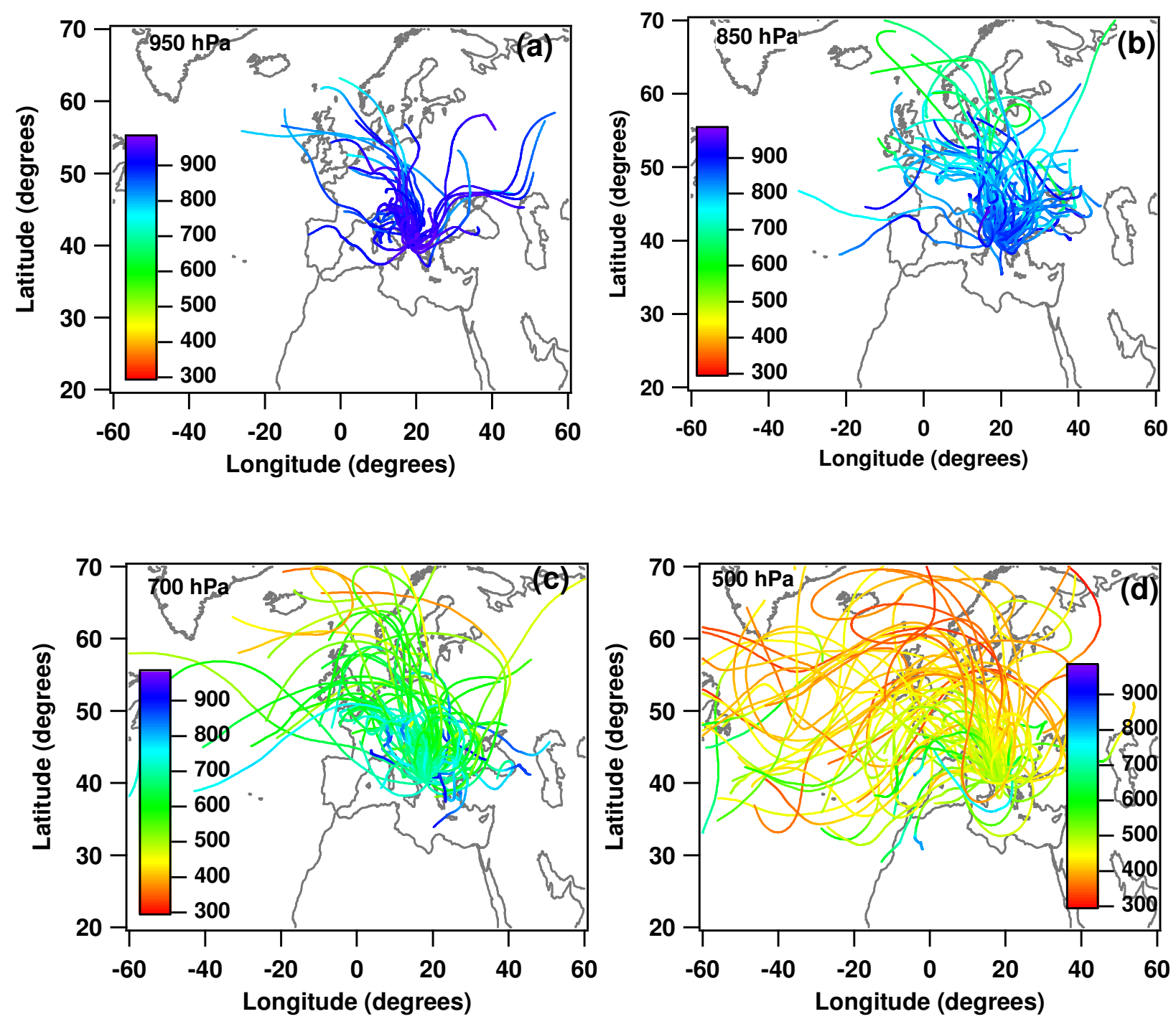

Fig. 2. 5-day backtrajectories of the measurement days with Sector A as aerosol source region for different arrival pressure levels: (a) $950 \mathrm{hPa}$, (b) $850 \mathrm{hPa}$, (c) $700 \mathrm{hPa}$, and (d) $500 \mathrm{hPa}$. Different colors are used to characterize pressure levels of each backtrajectory as a function of the time.

the monitoring site. Finally, we assumed Sector C as aerosol source region, if at least three of the four back trajectories with $950,850,700$, and $500 \mathrm{hPa}$ arrival pressure level, respectively, spent more than $40 \%$ of the time within the sector before reaching the sampling site. The peculiar geographical location of south-east Italy determined the use of different constraints on the number and time spent by backtrajectories in a Sector. The above reported criteria are the result of a sensitivity study that was performed to properly relate aerosol properties to source Sectors. In particular, the chosen Sector constraints allow selecting measurement days characterized by aerosol loads with $\AA$ and AOD values that concentrate in a particular area of the $\AA$-AOD scatterplot. We found that less restrictive constraints than those used allow selecting measurement days with aerosol loads characterized by
$\AA$ and AOD values that spread within all observed $\AA$-AOD variability range. The sensitivity study is not reported to do not lengthen the paper. Nevertheless, we know that criteria different than those used in this paper could have be chosen to infer aerosol source regions.

Considering the above reported criteria, we found that $32 \%$ of the 240 measurement days were characterized by air masses coming from Sector A, while 3\% of the measurement days were characterized by air masses coming either from Africa deserts (Sector B) or from the Atlantic and Mediterranean Sea (Sector C). As an example, Fig. 2a-d show for different arrival pressure levels, the backtrajectories of the measurement days with Sector A as aerosol source region. Different colors are used in Fig. 2a-d to characterize pressure levels of each backtrajectory as a function of the time. 

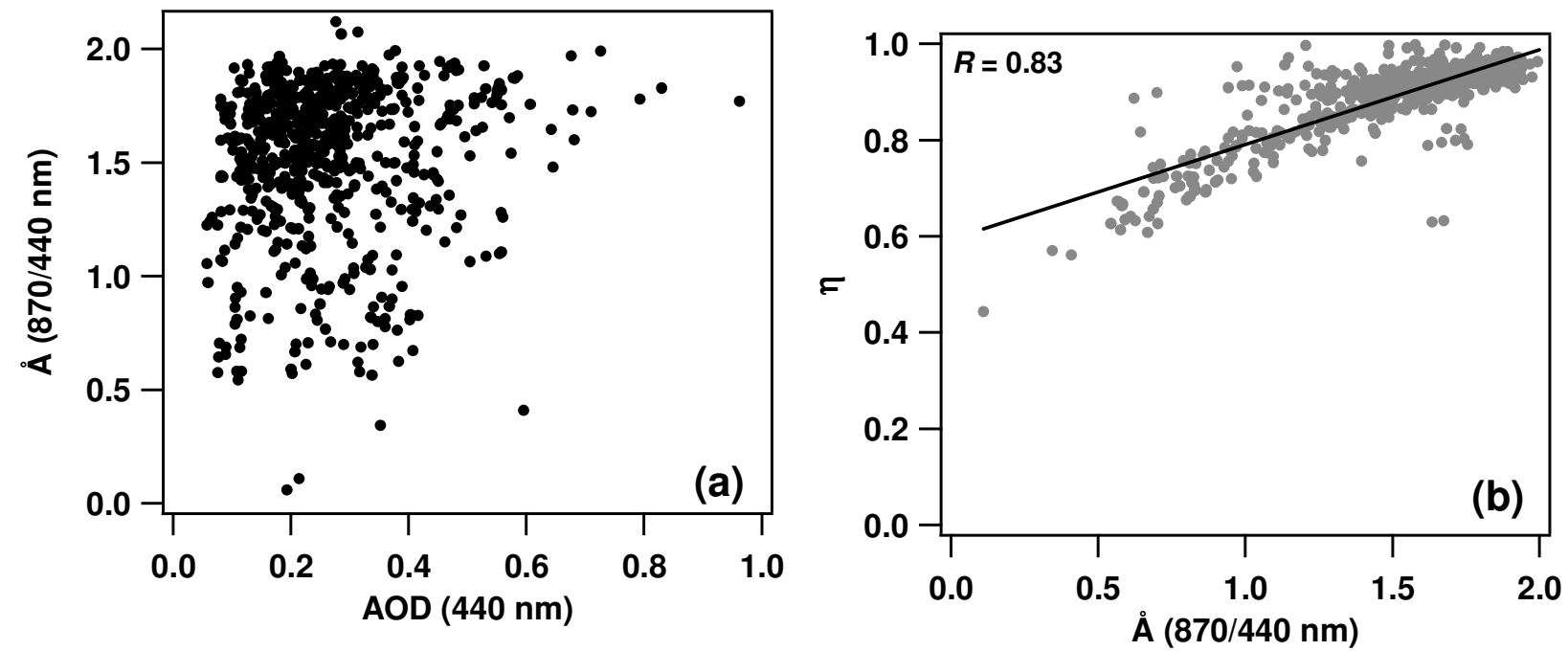

Fig. 3. (a) Scatter plot of the Angstrom coefficient $(\AA)$ calculated from AOD values at 870 and $440 \mathrm{~nm}$ and the AOD at $440 \mathrm{~nm}$ retrieved from 240 AERONET measurements days between March 2003 and October 2004; (b) scatter plot of the fine mode fraction $\eta$ at $440 \mathrm{~nm}$ versus $\AA$. The regression line fitting the data points (black line) and the corresponding correlation coefficient $R$ are also given in the figure.

Table 1. Measurement day percentages per Sector and per arrival pressure level.

\begin{tabular}{lcccc}
\hline Percentages & Sector A & Sector B & Sector C & Sector M \\
\hline Total & $32 \%$ & $3 \%$ & $3 \%$ & $62 \%$ \\
$950 \mathrm{hPa}$ & $29 \%$ & $0 \%$ & $1 \%$ & - \\
$850 \mathrm{hPa}$ & $30 \%$ & $2 \%$ & $3 \%$ & - \\
$700 \mathrm{hPa}$ & $28 \%$ & $3 \%$ & $3 \%$ & - \\
$500 \mathrm{hPa}$ & $10 \%$ & $3 \%$ & $3 \%$ & - \\
\hline
\end{tabular}

We mention that $62 \%$ of the measurement days were characterized by backtrajectories that do not allow defining the aerosol source sector. Aerosols monitored on these days are considered due mostly to mixed source regions (Sector M). The aerosol parameters of a measurement day characterized by a mixed advection pattern, are analyzed and discussed in the following section. Table 1 provides the measurementday percentages per Sector in addition to the percentages referring to the back trajectories having 950, 850, 700, and $500 \mathrm{hPa}$ arrival pressure level.

\section{Aerosol properties over south-east Italy}

A general description of the aerosol properties over the AERONET monitoring station is at first given in this section. Figure $3 \mathrm{a}$ shows the Angstrom coefficient calculated from AOD values at 870 and $440 \mathrm{~nm}$, versus the AOD at $440 \mathrm{~nm}$. AODs depend on aerosol load, while $\AA$ depends on the aerosol size distribution: typical values range from $\AA$ $>2.0$ for fresh smoke particles, which are dominated by ac- cumulation mode aerosols to nearly zero for large dust particles (Dubovik et al., 2000). Therefore, the $\AA$-AOD scatterplot gives us a qualitative indication on the aerosol load due to particles of different size: particles of different size (type) tend to concentrate in different areas of the plot and this can allow inferring aerosol of different origin. A total of 658 measurements derived from 240 measurement days are reported in Fig. 3a showing that $\AA$ and AOD values vary within the $0.1-2.2$ and the $0.1-1.0$ range, respectively. In addition, Fig. 3a reveals either that small particles $(1.2<\AA<2)$ leading to AODs within the 0.1-0.4 range are predominant and that highest AOD values $(>0.6)$ are due to fine mode particles. Aerosol size is a key parameter to separate natural from man-made aerosol. The anthropogenic aerosol is dominated by fine-mode particles, while natural aerosol contains a substantial component of coarse-mode particles (e.g. Kaufman et al., 2001). The AERONET inversion algorithm allows retrieving volume particle size distributions and all particles with radius $0.06 \mu \mathrm{m} \leq r<0.6 \mu \mathrm{m}$ are considered fine, while those with $0.6 \mu \mathrm{m} \leq r \leq 8.8 \mu \mathrm{m}$ are considered coarse. The predominant role of fine-mode particles over south-east Italy is better revealed by Fig. $3 \mathrm{~b}$ showing the fine mode fraction $\eta$ at $440 \mathrm{~nm}$ versus $\AA$. $\eta$ is the ratio between the fine-mode and the total optical depth at $440 \mathrm{~nm}$. We observe that $\eta$ values, which are quite correlated to $\AA$ values (correlation coefficient $=0.83$ ), vary within the $0.5-1.0$ range. In particular, $\eta$ values within the $0.8-1.0$ range are predominant $(88 \%)$. Hence, anthropogenic particles are predominant over southeast Italy and are responsible of the highest AODs.

It is worth observing that the comparison of Fig. 3a of this paper with Fig. 2 of the paper by Pace et al. (2006), and Fig. 5 of the paper by Fotiadi et al. (2006), provides 

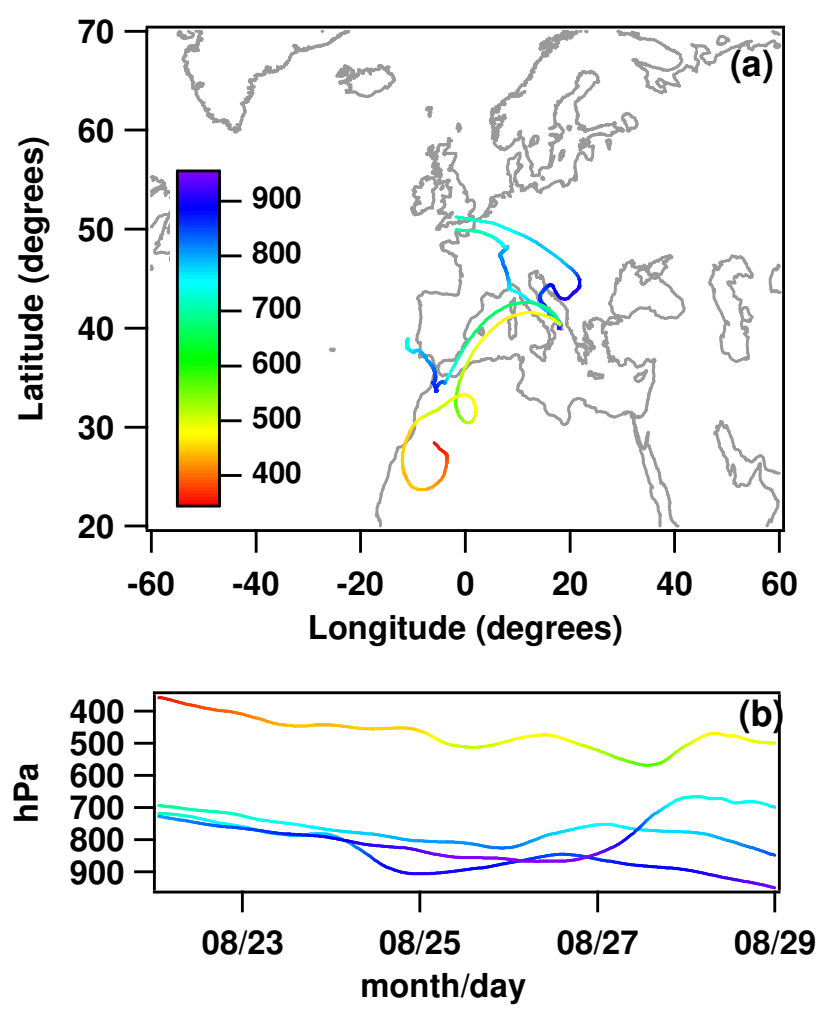

Fig. 4. (a) 5-day analytical backtrajectories of 29 August 2003 at 12:00 UTC arrival time; (b) altitude change as a function of time of each backtrajectory.

a quite significant indication on the dependence of the $\AA$ AOD scatter plot on the location of the monitoring site in the central-east Mediterranean Sea. The data reported by Pace et al. (2006) show, despite the results of this paper, that large-size particles characterized by $\AA$ values within the 0.5 0.3 range and by AOD values at $496 \mathrm{~nm}$ within the $0.2-0.8$ range are predominant at Lampedusa that is $\sim 140 \mathrm{~km}$ away from the Africa coast. Coarse mode particles are also responsible of the highest AOD values. According to Pace et al. (2006), the particles advected at Lampedusa from European countries, are responsible of $\AA$ and AOD values within the 1-2 and the 0.1-0.6 range, respectively. The amount and properties of aerosols in the eastern Mediterranean island of Crete were found by Fotiadi et al. (2006) to be strongly determined by the marine environment involving low concentrations of sea-salt aerosols produced by sea-spray, which constitute the background conditions. $\AA$ and AOD values were also influenced by dust aerosols mainly from African deserts, and secondarily from the Middle-East and Anatolian plateau. As a consequence, coarse mode particles also are predominant at Crete and are responsible of the highest AOD values. The transport of pollution fine aerosols from Europe and Turkey is responsible at Crete of the particles with $\AA$ values within the 1-2 range, in accordance with the results of Lampedusa and Lecce. However, fine-mode particles and hence, the aerosol of anthropogenic origin is responsible at Crete of AODs $<0.2$. The larger distance of Crete from continental polluted regions is responsible of these last results. In conclusion, the above reported discussion highlights that, in contrast to Lampedusa and Crete that are more affected by coarse mode particles mostly of natural origin, south-east Italy is more affected by fine-mode particles and hence by anthropogenic aerosol.

The aerosol parameters retrieved on 29 August 2003 are analyzed in this Section to show as an example, how aerosol properties can vary within few hours as a consequence of a mixed advection pattern. Figure 4 showing the backtrajectories of 29 August at 12:00 UTC, reveals that the 950 and $850 \mathrm{hPa}$ air masses are advected from Sector A, while the 700 and $500 \mathrm{hPa}$ air masses are advected from Sectors C and B, respectively. AERONET retrievals indicate that the aerosol monitored on the early morning (05:24 UTC) was characterized by $\AA=1.5$ and $\mathrm{AOD}=0.24$. In contrast, aerosol properties were characterized by $\AA=0.4$ and AOD $=0.4$ in the early afternoon (14:45 UTC). Grey arrows indicate in Fig. 5b the data points retrieved on 29 August. $\AA$ and AOD values indicate that fine-mode particles probably advected from northeast Europe were present over south-east Italy on the early morning. In contrast, coarse-mode particles (probably from north-west Africa) determining a quite large aerosol load were predominant on the afternoon. In addition to backtrajectories, MODIS images by Terra and Aqua satellites (http: //rapidfire.sci.gsfc.nasa.gov/realtime/2008029/) were used to support last comments: the image by Terra reveals that a dust plume was present over the Tyrrhenian Sea at 09:45 UTC, while the image by Aqua indicates that the dust plume was rather close to south-east Italy at 11:20 UTC.

The above reported discussion besides revealing the ability of the AERONET inversion algorithm to follow aerosol property changes shows the importance of using single measurements instead of daily averaged data, to properly characterize aerosol properties of different source regions.

\section{Aerosol properties and source regions}

AERONET products including AOD, single scattering albedo, asymmetry factor, Angstrom coefficient, fine-mode fraction, and lidar ratio are used in this section to characterize aerosol properties of different source regions. We mention that AOD, $\eta$, SSA, $g$, are the main parameters needed to incorporate aerosol particles into global climate models and evaluate aerosol direct radiative effects (Lyamani et al., 2004).

\subsection{Analysis of AOD and $\AA$ data for all Sectors}

Figure 5a shows $\AA$ versus AOD at $440 \mathrm{~nm}$ for the selected aerosol source Sectors: both grey open and full dots represent 

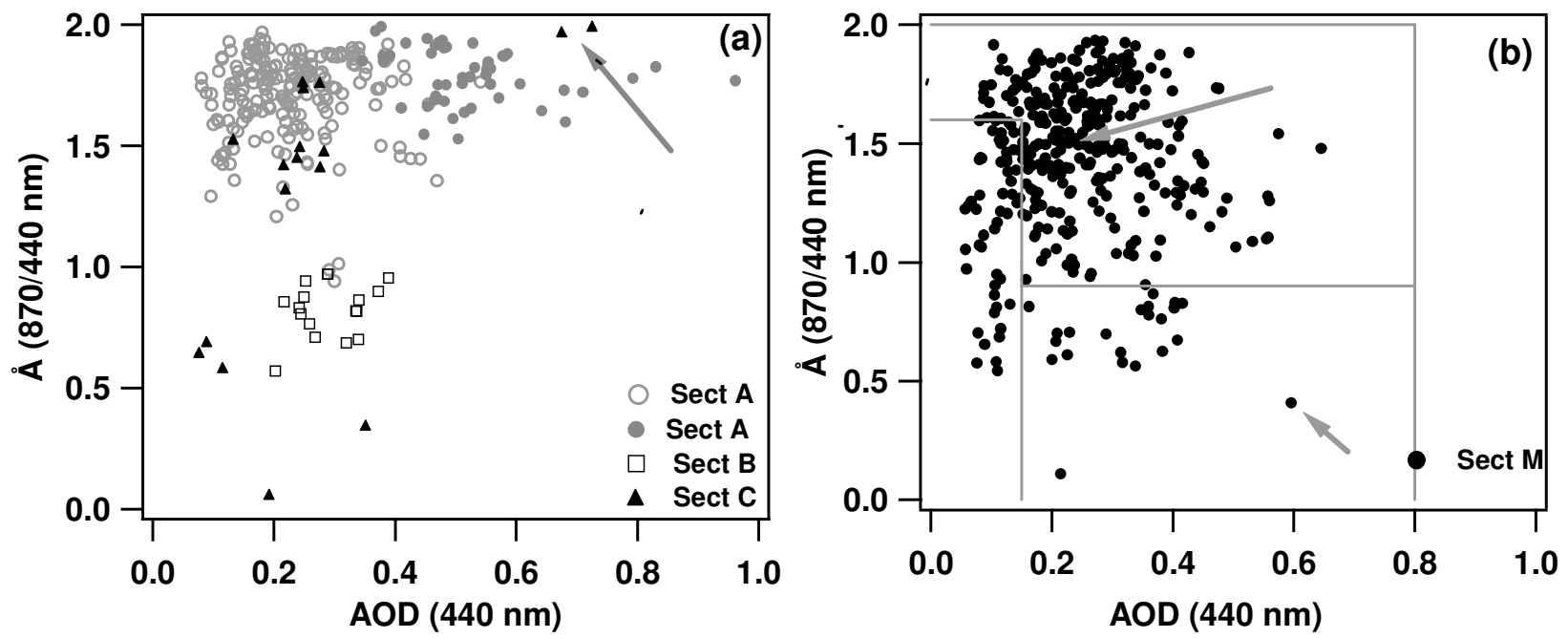

Fig. 5. (a) $\AA$ versus AOD at $440 \mathrm{~nm}$ for aerosol of different source Sectors: both grey open and full dots represent data referring to Sector A aerosol. In particular, grey full dots represent data that could be affected by the advection of biomass burning particles (BB).Open boxes and full triangles represent data of Sector B and C aerosol, respectively; (b) $\AA$ versus AOD of the Sector M aerosol. Grey solid lines represent the aerosol mask applied to the data points.
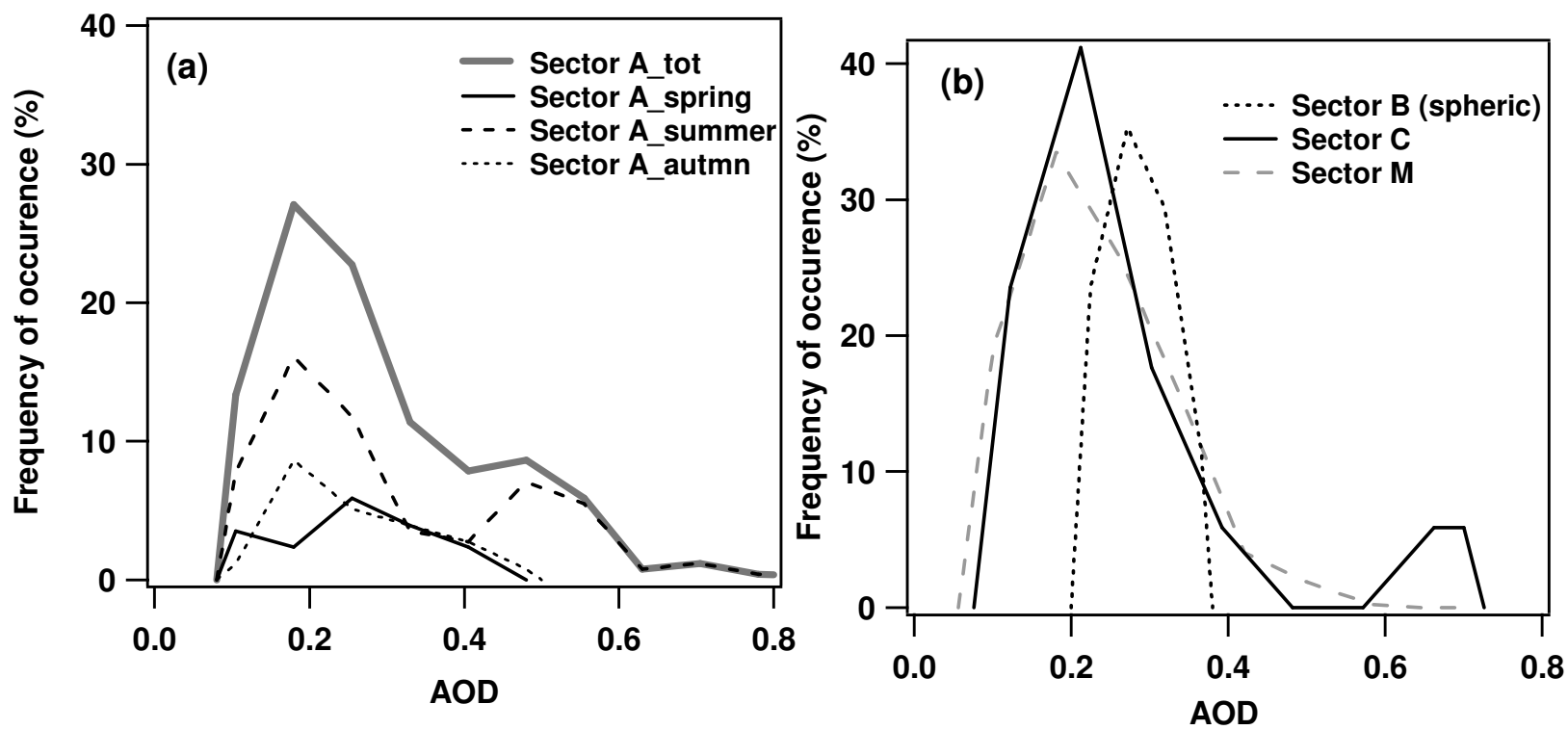

Fig. 6. (a) AOD frequency of occurrence plot for Sector A aerosol (grey line), and for summer (black dashed line), spring (black full line), and autumn (black dotted line) AOD data.; (b) AOD frequency plot of Sector B (dotted line), C (full black line), and M (dashed grey line) aerosol.

data referring to the Sector A aerosol. In particular, grey open dots represent the parameters of aerosol loads advected from the urban/industrial Sector A regions. In contrast, grey full dots represent the parameters of aerosol loads also affected by the advection of biomass burning particles from Sector A regions. In addition to backtrajectories, fire maps retrieved by MODIS satellite images were used (http://maps. geog.umd.edu/firms/) to infer the advection of biomass burn- ing particles over south-east Italy. Open boxes and full triangles in Fig. 5a represent aerosol data of the Sector B and C aerosol, respectively. We observe from Fig. 5a that fine-mode particles $(0.94<\AA<2.0)$ that are also responsible of the highest AODs are advected over south-east Italy from Sector A. In contrast, large size particles $(0.57<\AA<0.96)$ are advected from Sector B. Particles of variable size that are on average responsible of rather low AODs are advected from Sector C. 

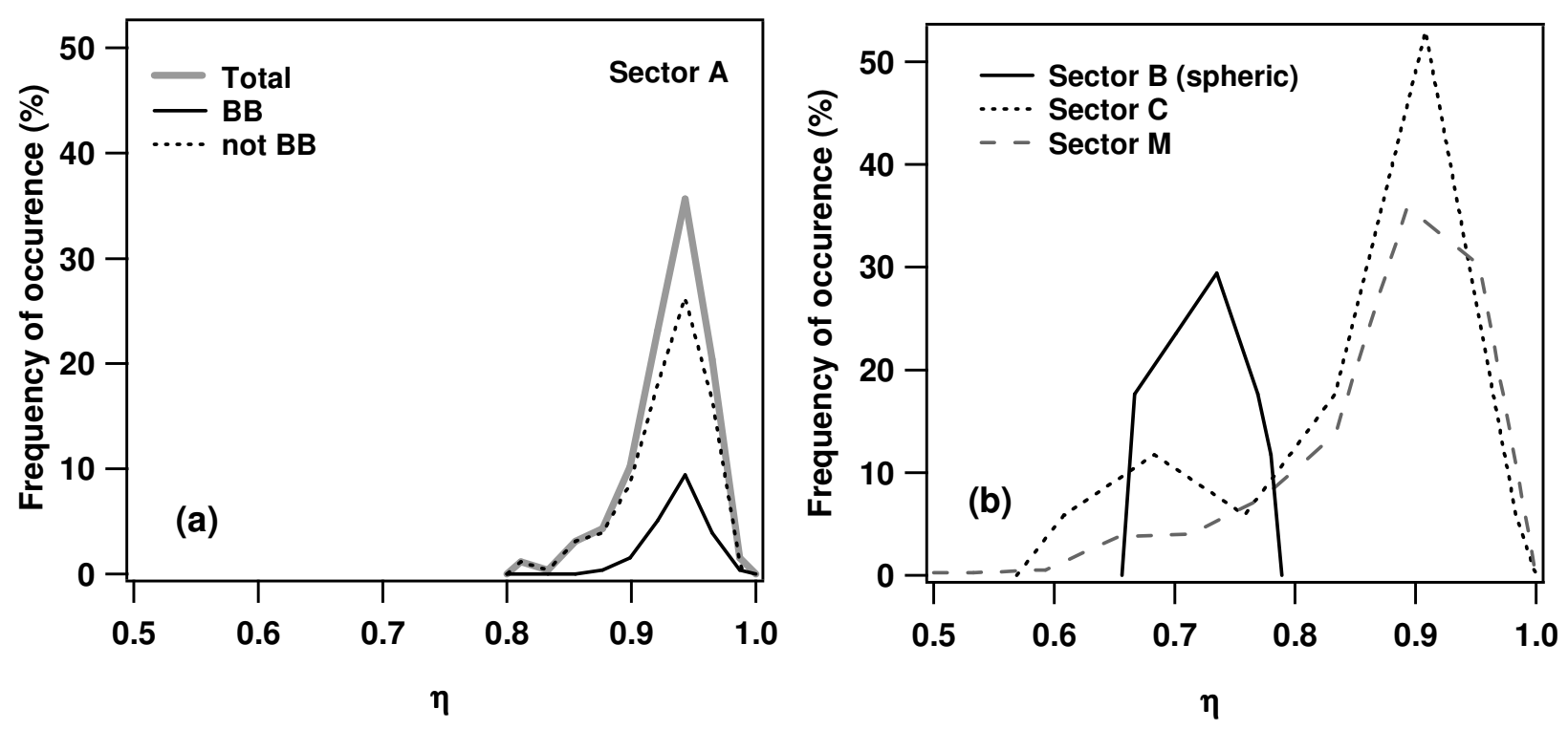

Fig. 7. (a) $\eta$ frequency of occurrence plot of Sector A aerosol (grey line). Black and dotted lines represent in the figure data referring to aerosol affected (BB) and not-affected (not BB) by biomass burning particles, respectively, (b) $\eta-$ frequency distribution plot for particles advected from Sector B (black dotted line), from Sector C (black line) and from Sector M (grey dashed line).

The results of Fig. 5a are in accordance with previous studies (e.g. Pace et al., 2006; Fotiadi et al., 2006). The aerosol from Sector A, which travels over urban/industrial environments before getting to the monitoring site, is dominated by fine-mode particles (Remer and Kaufman, 1998; Dubovik et al., 2002), while the one advected from desert regions (Sector B) is strongly dominated by coarse-mode particles. Sector C data (Fig. 5a, full triangles) show that in maritime conditions, the relative contribution of coarse particles, although variable (Smirnov et al., 2002), is generally higher than that in urban/industrial environments and lower than that for desert dust (Dubovik et al., 2002).

Figure $5 b$ shows $\AA$ versus AOD for aerosol loads monitored on measurement days for which it was not possible to infer the aerosol source sector in accordance with the criteria defined in Sect. 3 (Sector M). Variability ranges of both $\AA$ and AOD values are rather similar to those of Fig. 5a. Hence, Sector M aerosol parameters (Fig. 5b) are similar to the combination of the aerosol parameters that characterize particles from Sector A, B, and C.

Figure 6a (grey line) shows the AOD frequency of occurrence plot of the total Sector A aerosol, and for summer (black dashed line), spring (black full line), and autumn (black dotted line) measurements. Data points of winter months were not available for the lack of AERONET measurements. We observe from Fig. 6a (dashed line) that the summer-AOD frequency plot is bimodal with a main peak at $\sim 0.2$ and a secondary peak at $\sim 0.5$. Figure $5 \mathrm{a}$ indicates that AOD values larger than 0.4 are mostly due to aerosol affected by biomass burning particles. In fact, most of forest fires occur on summer. Hence, AODs $<0.4$ are mostly due to con- tinental urban/industrial aerosol. Figure 6a shows that AOD values of autumn (dotted line) and spring (solid black line) measurements are smaller (0.08-0.5) than those retrieved on summer, as it is generally observed over the Mediterranean basin (e.g. Gerasopoulos, 2005), where the aerosol load is on average larger in summer for the lack of rainy days, which favor the accumulation of aerosol particles and for the larger solar irradiance that favors the production of photochemical smog. Figure $6 \mathrm{~b}$ shows for comparison the AOD frequency plot of the Sector B- (dotted line), C- (full black line), and Maerosol (dashed grey line). We observe from Fig. $6 \mathrm{~b}$ that particles from Sector $\mathrm{C}$ and $\mathrm{M}$ are responsible of AODs varying up 0.7. In contrast, Sector B AODs vary within the $0.2-0.4$ range with an average of $0.29 \pm 0.05$.

\subsection{Sector A: analysis of $\eta$, SSA, $g$, and $L r$ parameters}

Figure 7a (grey line) shows the $\eta$ frequency of occurrence plot of the total Sector A aerosol and for the aerosol affected (black line) and not-affected (dotted line) by biomass burning particles. $\eta$-values span the $0.8-1.0$ range and are peaked at $\sim 0.94$. The SSA- and the $g$ - frequency distribution plot of the total Sector A aerosol are shown in Fig. 8a (grey line) and $9 \mathrm{a}$ (grey line), respectively. Black and dotted lines represent in both figures data referring to aerosol affected and not-affected by biomass burning particles, respectively. 1.5 level SSA data were plotted in Fig. 8a, since level 2 data were not available. We observe from Fig. 8a (grey line) that SSA values vary between 0.8 and 1 with an average of $0.93 \pm 0.03$. Figure 9 a (grey line) reveals that $g$ values vary within the $0.6-0.74$ range with an average of $0.67 \pm 0.03$. The 
Table 2. Variability ranges, yearly average with standard deviations and number of data points $(N)$ of the investigated parameters for air-masses originating from different sectors.

\begin{tabular}{lccccc}
\hline & Sector A & Sector B (Spheric) & Sector B (Spheroid) & Sector C & Sector M \\
\hline$N$ & 255 & 17 & 17 & 17 & 369 \\
AOD Aver & $0.29 \pm 0.15$ & $0.29 \pm 0.05$ & $0.29 \pm 0.05$ & $0.27 \pm 0.17$ & $0.24 \pm 0.11$ \\
AOD Min & 0.08 & 0.20 & 0.20 & 0.07 & 0.05 \\
AOD Max & 0.96 & 0.38 & 0.39 & 0.72 & 0.64 \\
$\eta$ Aver & $0.93 \pm 0.03$ & $0.73 \pm 0.04$ & $0.72 \pm 0.05$ & $0.8 \pm 0.1$ & $0.87 \pm 0.09$ \\
$\eta$ Min & 0.80 & 0.65 & 0.61 & 0.57 & 0.44 \\
$\eta$ Max & 0.99 & 0.78 & 0.79 & 1.0 & 1.0 \\
SSA Aver & $0.93 \pm 0.03$ & $0.94 \pm 0.04$ & $0.94 \pm 0.03$ & $0.94 \pm 0.03$ & $0.93 \pm 0.03$ \\
SSA Min & 0.82 & 0.84 & 0.89 & 0.90 & 0.75 \\
SSA Max & 0.99 & 0.99 & 0.99 & 0.98 & 0.99 \\
$g$ Aver & $0.67 \pm 0.03$ & $0.69 \pm 0.02$ & $0.69 \pm 0.02$ & $0.67 \pm 0.03$ & $0.68 \pm 0.03$ \\
$g$ Min & 0.60 & 0.64 & 0.65 & 0.61 & 0.58 \\
$g$ Max & 0.74 & 0.72 & 0.72 & 0.71 & 0.75 \\
LrAver & $72 \pm 20$ & $43 \pm 15$ & $56 \pm 13$ & $58 \pm 24$ & $57 \pm 23$ \\
Lr Min & 20.48 & 8.7 & 37 & 10 & 9.3 \\
Lr Max & 120 & 65 & 80 & 87 & 107 \\
\hline
\end{tabular}
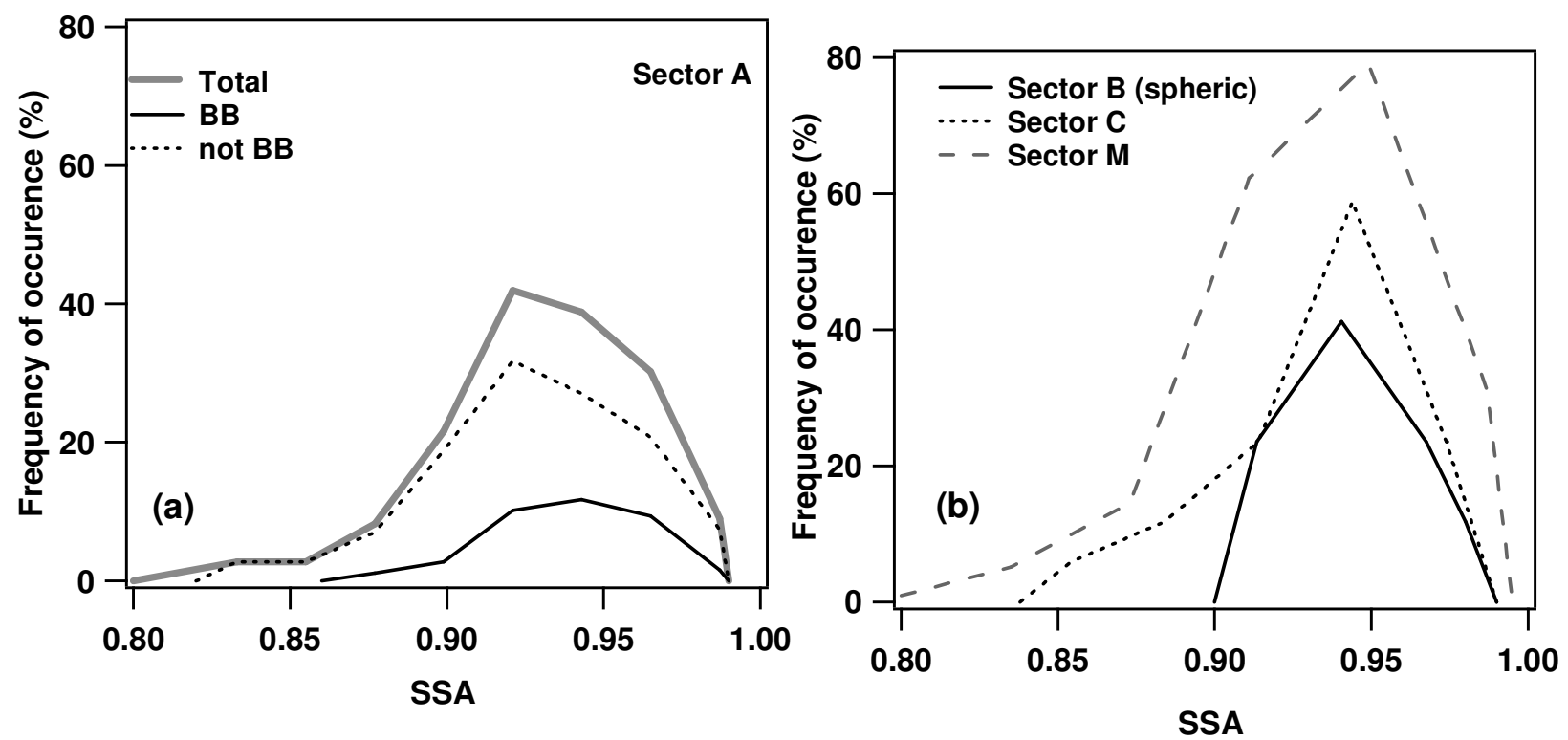

Fig. 8. (a) SSA frequency of occurrence plot of Sector A aerosol (grey line). Black and dotted lines represent in the figure data referring to aerosol affected (BB) and not-affected (not BB) by biomass burning particles, respectively. (b) SSA-frequency distribution plot for particles advected from Sector B (black dotted line), from Sector C (black line) and from Sector M (grey dashed line).

comparison between the solid- and the dotted-black line both in Fig. 8a and in Fig. 9a, shows that the variability range of SSA and $g$ values extends toward lower values for the aerosol not affected by biomass-burning particles, as a consequence of the larger presence of smaller-size, more-absorbing particles. Variability ranges and mean values of the aerosol parameters above analyzed are given in Table 2. According to d' Almeida et al. (1991) and Hess et al. (1998), AOD, $\eta$, SSA, and $g$ frequency distribution plots indicate that the
Sector A aerosol can be considered representative of "continental average aerosol", mostly made of water soluble and a small amount of soot and insoluble components. A closure study between a 2.5-year data set of Raman lidar measurements (performed in Lecce within the European Aerosol Research Lidar Network) and a numerical model, also indicated that rather clean continental aerosols, with watersoluble fine-mode aerosol accounting for $98-99 \%$ of the total number of particles, characterized the aerosol load advected 

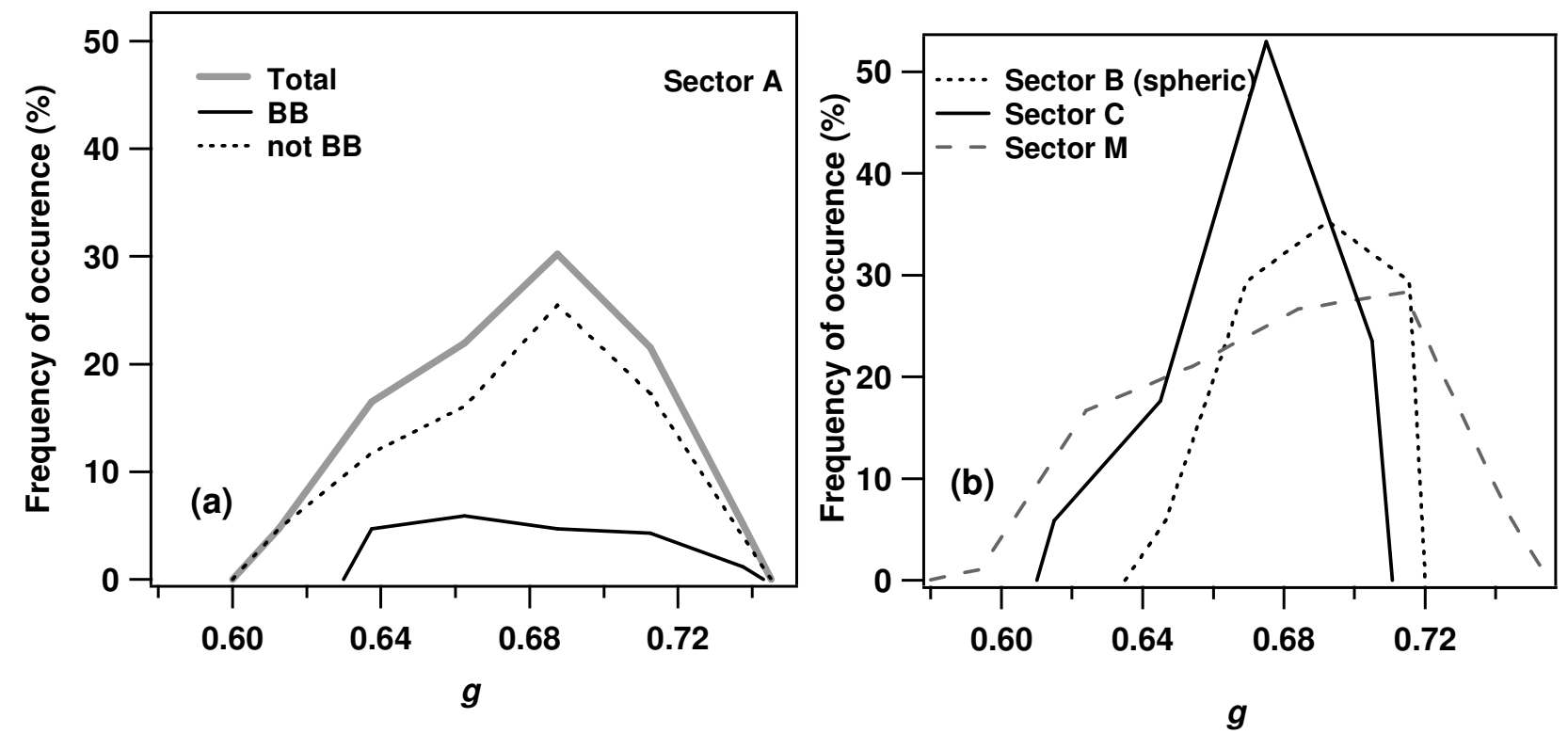

Fig. 9. (a) $g$ frequency of occurrence plot of Sector A aerosol (grey line). Black and dotted lines represent in the figure data referring to aerosol affected (BB) and not-affected (not BB) by biomass burning particles, respectively. (b) $g-$ frequency distribution plot for particles advected from Sector B (black dotted line), from Sector C (black line) and from Sector M (grey dashed line).

over south-east Italy from north and east European countries (Barnaba et al., 2007).

The lidar ratio $\mathrm{Lr}$ that is mainly retrieved from Raman lidar measurements (e.g. De Tomasi et al., 2006) also is used to characterize aerosols of different type. $L r$ at the wavelength $\lambda$ is calculated from AERONET products according to the following equation (e.g. Muller et al., 2003; Cattrall et al., 2005):

$$
\operatorname{Lr}(\lambda)=\frac{4 \pi}{S S A(\lambda) P\left(\lambda, 180^{\circ}\right)}
$$

where $P\left(\lambda, 180^{\circ}\right)$ represents the phase function at $180^{\circ}$. Figure 10a (grey solid line) shows the $L r$ frequency of occurrence plot for $\lambda=440 \mathrm{~nm}$ and for the total Sector A aerosol. Black and dotted lines represent in Fig. 10a the $L r$ frequency of distribution plot due to aerosol affected and not-affected by biomass burning particles, respectively. Figure 10a (grey solid line) reveals that total $L r$ values vary between 20 and $120 \mathrm{sr}$ and are peaked at $\cong 80 \mathrm{sr}$. These data are in satisfactory accordance with those retrieved by Raman lidar measurements at $351 \mathrm{~nm}$ performed in Lecce during 2.5 year measurements, which provided lidar ratios spanning the 5130 sr range (Barnaba et al., 2007) for air masses advected from north and east-European countries. Figure 10a (black solid line) indicate that $70 \%$ of the $L r$ values due to aerosol affected by biomass burning particles vary within the 40$80 \mathrm{sr}$ range. Cattrall et al. (2005) analyzing AERONET measurements from 26 sites across the world, also revealed that lidar ratios at $550 \mathrm{~nm}$ of biomass-burning aerosol varied within the $40-80 \mathrm{sr}$ range and were peaked at $60 \mathrm{sr}$, in accordance with the results of this paper. In addition, Cattrall et al. (2005) found that the urban-industrial aerosol was characterized by $\mathrm{Lr}$ values varying within the 40-100 sr range and peaked at $71 \mathrm{sr}$. Figure 10a (black dotted line) showing $L r$ values of urban/industrial aerosol not affected by biomass burning particles, reveals that $L r$ values vary within the $20-120 \mathrm{sr}$ range and that $70 \%$ of the $L r$ values vary within the $85-120 \mathrm{sr}$ range, in accordance with the results by Cattrall et al. (2005) for urban/industrial aerosol. In conclusion, the above reported analysis indicates that air masses carrying moderately-absorbing $(0.8<\mathrm{SSA}<1.0$ and $20 \mathrm{sr}<L r<120 \mathrm{sr})$, fine-mode $(0.8<\eta<1.0$ and $0.6<g<0.8)$ particles are advected over south-east Italy and hence over the central Mediterranean basin, from the urban/industrial European countries. In addition, during summer, these air-masses are responsible for rather high aerosol loads (AOD>0.5) contributed by biomass burning aerosol.

Finally, it is worth noting from Table 2 that $88 \%$ of the 289 classified data points are representative of the "continental average aerosol" advected from Sector A source regions. Hence, the aerosol advected from Sector A is predominant over that advected from Sector B and C.

\subsection{Sector B: analysis of $\eta$, SSA, $g$, and $L r$ parameters}

Figures 7b-10b show by black dotted lines $\eta$, SSA-, $g-$, and $L r$-frequency distribution plots for aerosol particles from Sector B. Variability ranges and average values of the investigated parameters are given in Table 2. All data of Figs. $7 b-10 b$ were retrieved for aerosol particles that are 

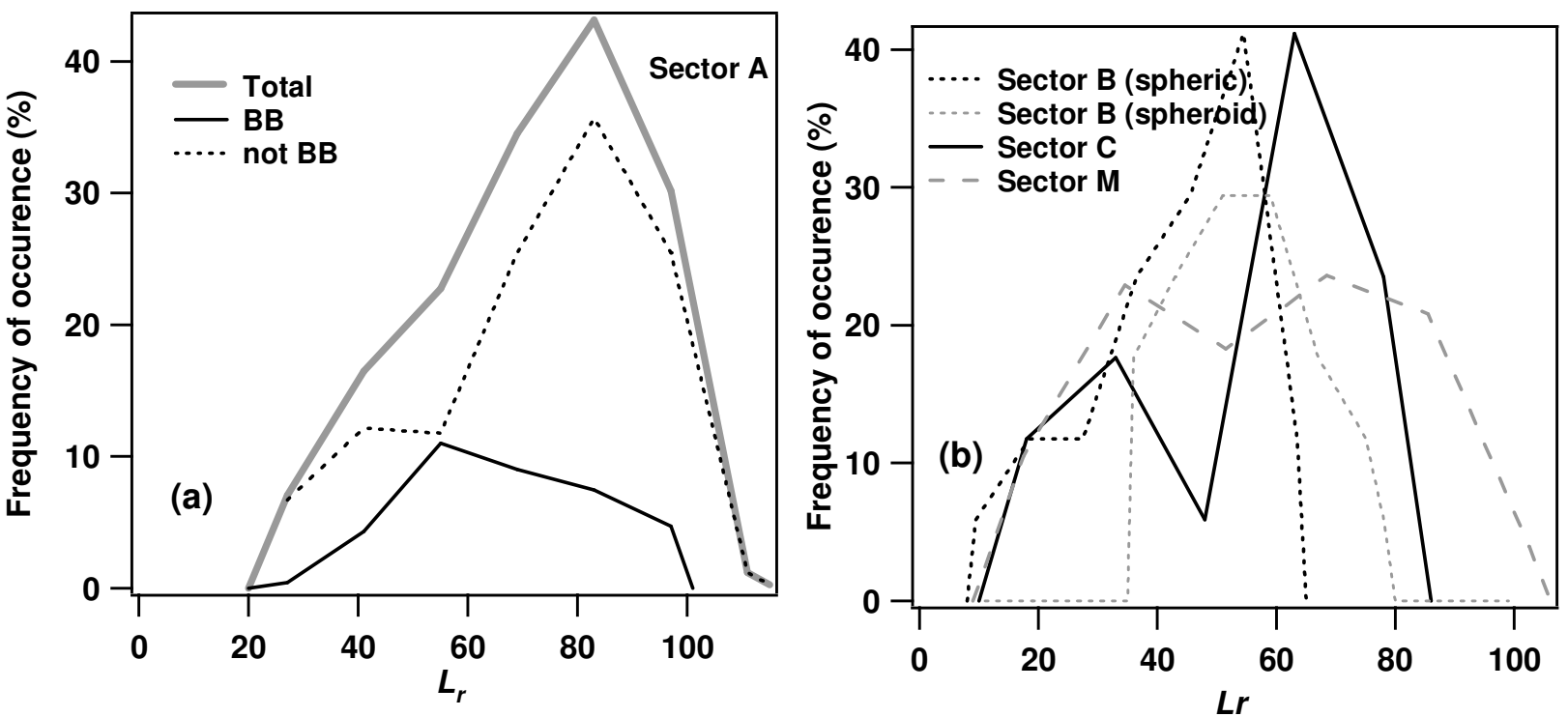

Fig. 10. (a) $L r$ frequency of occurrence plot for $\lambda=440 \mathrm{~nm}$ of Sector A aerosol (grey line) and for aerosols affected (black solid line) (BB) and not-affected (black dotted line) (not BB) by biomass burning particles, respectively. (b) $L r$-frequency distribution plot for particles advected from Sector B (black dotted line), Sector C (black line) and Sector M (grey dashed line). The grey dotted line represents the - Lr frequency distribution plot of the values calculated by the spheroid model.

assumed to be polydisperse homogeneous spheres with the same complex refractive index. However, it is well known that latter assumption misleads AERONET inversion products when the aerosol load is significantly affected by nonspherical particles and aerosols from Sector B are significantly affected by desert type particles, which are flattened and irregular in shape (Dubovik et al., 2000). The particle non-sphericity leads to a not-negligible reduction of the backscatter efficiency compared to the one of surface equivalent spheres (e.g. Barnaba et al., 2005). As a result, there have been numerous efforts to account for particle nonsphericity in aerosol retrieval algorithms (e.g. Dubovik et al., 2002; Mishchenko et al., 2003). It was shown by Dubovik et al. (2006) that in dust dominated environments the use of polydisperse, randomly oriented spheroids leads to a significant improvement in retrieving the size distribution and real refractive index (Dubovik et al., 2002). A spheroid (ellipsoid of revolution) is the simplest nonspherical shape that can generalize the spherical shape (a sphere is a spheroid with an axis ratio equal to one). Variability ranges and average values of the Sector B aerosol parameters retrieved by the spheroid model are given in Table 2 . The comparison between $\eta$-, SSA-, and $g$ - values by the spheroid and the spherical model revealed that the percentage variations were lower than $5 \%$. In contrast, lidar ratio values by the spheroid model were significantly larger than the values provided by the spherical model: percentage variations of the values provided by the two models were as high as $100 \%$ (e.g. Barnaba et al., 2005). In accordance with Eq. (1), the lidar ratio increases with the backscatter efficiency reduction.
Figure $10 \mathrm{~b}$ shows by grey dotted line the frequency distribution plot of $L r$ values by the spheroid model and we observe that the lidar ratio values vary within the $37-80$ sr range with an average of $56 \pm 13 \mathrm{sr}$. These results are in satisfactory accordance with those reported by Cattrall et al. (2005). Analyzing AERONET aerosol products of Africa and Saudi Arabia sites significantly affected by desert dust, they found at $550 \mathrm{~nm}$ that lidar ratio values by the spherical model varied within the 10-20 sr range and were peaked at $15 \mathrm{sr}$. In contrast, lidar ratios by the spheroid model were peaked at $42 \mathrm{sr}$ and varied within the 20-60 sr range. The results of Fig. 10b (grey dotted line) are also in satisfactory accordance with $\mathrm{Lr}$ values retrieved over south-east Italy by Raman-lidar measurements at $351 \mathrm{~nm}$ (e.g. De Tomasi et al., 2003), which combined with model calculations, revealed that an average lidar ratio of $47 \mathrm{sr}$ could be used to characterize Sahara dust particles over south-east Italy (Barnaba et al., 2004).

$\eta$ values that vary within the $0.61-0.79$ range (Table 2 ) indicate that the Sector B aerosol advected to south-east Italy is also quite affected by the contribution of fine-mode particles. In fact, a recent Sahara dust event study by complementary remote sensing measurements and ground observations revealed that the anthropogenic fine mode aerosol was over south-east Italy more than $50 \%$ of the total aerosol load during a dust outbreak (Bellantone et al., 2008). $\eta$ values smaller than 0.5 were generally retrieved both at Lampedusa and Crete during dust outbreaks. The larger $\eta$ values retrieved over south-east Italy may be partially due to the sedimentation of large-size dust particles, since south-east Italy is at a larger distance from desert source regions than Lampedusa 


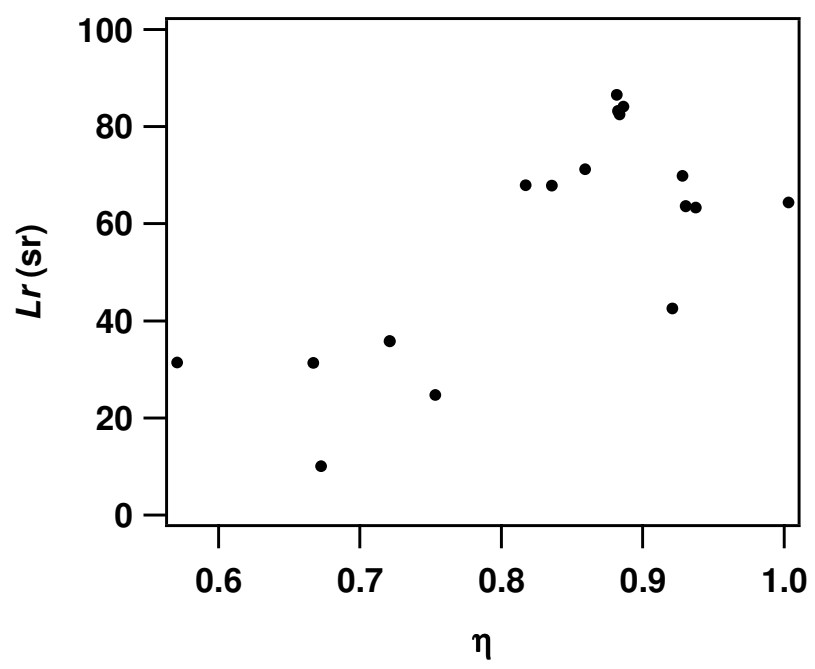

Fig. 11. $L r$ values by the spheroid model versus $\eta$ of the Sector $\mathrm{C}$ aerosol.

and Crete. However, the contribution of polluted particles from marine and continental areas crossed by the desert air masses before reaching south-east Italy can represent a significant contributing factor. SSA and $g$ variability ranges and average values support last comment. According to Dubovik et al. (2002) desert dust at Cape Verde was characterized at $440 \mathrm{~nm}$ by SSA $=0.93 \pm 0.01$ and $g=0.73 \pm 0.04$. In contrast, Table 2 shows both that SSA values span the 0.89-0.99 range with an average of $0.94 \pm 0.03$, and that $g$ values span the $0.65-0.72$ range with an average of $0.69 \pm 0.02$. The larger (smaller) SSA $(g)$ mean value found over south-east Italy with respect to that of Cape Verde can be explained by assuming that desert dust particles advected over south-east Italy were also affected by the contribution of moderatelyabsorbing, fine-mode particles. Finally, we mention that Table 2 reveals that only $6 \%$ of the 289 Sector A-C data points were representative of polluted desert-dust aerosol advected from Sector B source regions. As a consequence, desert-dust is a minor aerosol component over south-east Italy.

\subsection{Sector C: analysis of the $\eta, \mathrm{SSA}, g$, and $L r$ parameters}

Black lines represent in Figs. 7b-10b $\eta-$, SSA-, g-, and $L r-$ frequency distribution plots of Sector $\mathrm{C}$ aerosol. Variability ranges and mean values of the investigated parameters are given in Table 2, which also shows that AODs span the 0.070.72 range with a mean value of about $0.27 \pm 0.17$. According to Hess et al. (1998) and Smirnov et al. (2003) clean maritime particles are responsible of AODs at $440 \mathrm{~nm}$ smaller than 0.2. Hence, the Sector $\mathrm{C}$ aerosol is expected to be maritime polluted. SSA- and $g$ - variability ranges support last comment. According to d'Almeida et al. (1991), sea-salt and oceanic particles are characterized at $450 \mathrm{~nm}$ by SSA and $g$ values close to 1 and 0.79 , respectively. In addition, Dubovik et al. (2002) showed that the oceanic aerosol is characterized at
$440 \mathrm{~nm}$ by $\mathrm{AOD} \leq 0.15, \mathrm{SSA}=0.98 \pm 0.03$, and $g=0.75 \pm 0.04$. Despite the results by d'Almeida et al. (1991) and Dubovik et al. (2002), Fig. 8b (solid line) shows that SSA values span the $0.90-0.98$ range with a mean value of $0.94 \pm 0.03$ and Fig. $9 b$ reveals that $g$ values that span the 0.61-0.71 range, have a mean value of $0.67 \pm 0.03$. The smaller SSA and $g$ values of this paper with respect to the ones reported by d'Almeida et al. (1991) and Dubovik et al. (2002) for marine aerosol can be explained by assuming that fine-mode and moderatelyabsorbing particles of non-marine origin affect the Sector C aerosol. In fact, the rather high AOD values indicated by the arrow in Fig. 5a are possibly due to contamination by biomass burning particles. They were retrieved on 9 September 2003 at 15:37 UTC and 14:07 UTC, respectively and in accordance with bactrajectories and satellite fire maps, the air masses advected from the Atlantic crossed fire affected sites before reaching south east Italy. The marked bimodal structure of both the $\eta$ - and the $L r$-frequency distribution plot (Figs. 7b and 10b, solid line) and Fig. 11 showing the $L r$ versus $\eta$ scatterplot, also allow inferring that two main aerosol classes contribute to the Sector $\mathrm{C}$ aerosol. We observe from Fig. 11 that $L r$ values span the 10-36 sr range when $\eta$ values vary within the $0.57-0.75$. In contrast aerosol loads characterized by $\eta$ values spanning the $0.8-1.0$ range are characterized by $L r$ values varying within the $42-86 \mathrm{sr}$ range. According to Ackerman (1998), the maritime aerosol is characterized at $355 \mathrm{~nm}$ by $L r$ values varying within the 17-24 sr range, while the continental aerosol, which consists of insoluble, soot, and water soluble components, is characterized by lidar ratios spanning the $43-70 \mathrm{sr}$ range. Cattrall et al. (2005) revealed that at $550 \mathrm{~nm}$, lidar ratio values of oceanic particles spanned the $20-40 \mathrm{sr}$ range, while $L r$ values of urban/industrial aerosol varied within the $40-100$ sr range. In addition, Cattrall et al. (2005) showed that oceanic particles were characterized by Angstrom coefficient values spanning the $0.3-1.2$ range, while $\AA$ values of urban/industrial aerosol varied within the 1.6-2.0 range. Finally, lidar measurements over south-east Italy by an elastic-Raman lidar operating at $351 \mathrm{~nm}$, combined with model calculations, revealed that an average lidar ratio of $29 \mathrm{sr}$ can be used to characterize maritime aerosols (Barnaba et al., 2004) over south-east Italy. In accordance with the above reported discussion, the Sector C aerosol characterized by $L r$ and $\eta$ values spanning the 10 $36 \mathrm{sr}$ and the $0.57-0.75$ range, respectively can be considered of maritime type. In contrast, the Sector $\mathrm{C}$ aerosol characterized by $L r$ and $\eta$ values spanning the $42-86 \mathrm{sr}$ and the $0.8-1.0$ range, respectively can be considered of maritime-polluted type. Last results are mostly determined by the geographical location of south-east Italy: oceanic particles generally cross urban/industrial area in the Mediterranean basin before reaching south-east Italy. Barnaba et al. (2004) also showed that the classification of cases of clean marine aerosols was particularly complex in the Mediterranean, due to the influence of the surrounding continents and the limited dimension of the basin. 


\subsection{Sector M: analysis of $\eta$, SSA, $g$, and $L r$ parameters}

In accordance with the backtrajectory analysis and the criteria defined in Section 3, 62\% of the 240 measurements days were characterized by advection patterns that did not allow defining the aerosol source Sector (Sector M). Frequency distribution plots of AOD, $\eta$, SSA, $g$, and $L r$ values of the Sector $\mathrm{M}$ aerosol are plotted in Figs. $6 \mathrm{~b}-10 \mathrm{~b}$ by grey dashed lines. Variability ranges and mean values of Sector $\mathrm{M}$ aerosol parameters are given in Table 2. Both Table 2 and Fig. 5 indicate that Sector $\mathrm{M}$ aerosol parameters are similar to the combination of the aerosol parameters that characterize particles from Sector A, B, and C.

The mixing of different particle types is mainly expected to occur when the advection pattern changes with time of the day and as a consequence, it is not possible to infer the aerosol source Sector. A typical example of measurement day characterized by a mixed advection pattern was analyzed in Section 4, where it was shown that the aerosol properties significantly varied within few hours as a consequence of the advection pattern change.

The aerosol mask method (Barnaba and Gobbi, 2004), which represents a valuable tool to classify aerosol of different type, was applied to the Sector M data points of Fig. $5 \mathrm{~b}$ to separate the contribution of maritime, continental and desert dust aerosol: the main aerosol components over the Mediterranean basin. According to Dubovik et al. (2002), we assumed that maritime particles were represented in the $\AA$ versus AOD scatterplot of Fig. $5 \mathrm{~b}$ by the data points with $\mathrm{AOD}<0.15$ and $\AA \leq 1$.6. Data points characterized by AOD $\geq 0.15$ and $\AA \leq 0.9$ were considered representative of desert dust particles, while all the data points that could not be ascribed to maritime and desert dust particles were considered representative of continental urban/industrial particles. Solid lines in Fig. 5b define the data point areas that are representative of different aerosol types. In accordance with the aerosol mask criteria, it was found that $6 \%, 14 \%$, and $80 \%$ of the 369 data points of Fig. $5 \mathrm{~b}$ were representative of desert dust, maritime and continental aerosol particles, respectively. Latter results are in satisfactory accordance with the percentage values obtained by analyzing bactrajectories to infer the aerosol contribution from Sector A, B, and C source regions, respectively. Hence, aerosol mask results further more show that the contribution of continental urban/industrial aerosol was predominant over south-east Italy and that Sector M aerosol properties were similar to the ones obtained by combining Sector A, B, and C aerosol properties. The comparison between the Sector M AOD frequency of occurrence plot with the AOD frequency of occurrence plot due to the total aerosol load from Sector A, B, and C, revealed that the differences were lower than $5 \%$.

\section{Summary and conclusion}

Aerosol measurements from the AERONET station in Lecce over south-east Italy, combined with five-day backtrajectories were analyzed to characterize aerosol properties over the Central Mediterranean basin, to assess the influence to the aerosol load of long-range transport from various regions, and to study the mixing of different aerosol types. The aerosol data include AOD, single scattering albedo, asymmetry factor, Angstrom coefficient, fine-mode fraction, and lidar ratio retrieved from measurements performed in the period March 2003-October 2004. 5-day analytical backtrajectories were also used to characterize main advection patterns over the Lecce AERONET site. In particular, three broad geographical sectors were defined as aerosol source regions: Sector A, which includes all continental European sources with the exception of Spain; Sector B, which includes the Southern Mediterranean Sea and the Africa continent; Sector $\mathrm{C}$, which includes the Western Mediterranean, the Iberian Peninsula, and the Atlantic Ocean. The time spent by the trajectories in a Sector up to the measurement day was also considered to better define the aerosol origin sector. We found that $32 \%$ of the 240 measurement days were characterized by air masses coming from Sector A, while $3 \%$ of the measurement days were characterized by air masses coming either from Africa deserts (Sector B) or from the Atlantic and Mediterranean Sea (Sector C). $62 \%$ of the measurement days were characterized by backtrajectories that did not allow defining the aerosol source Sector according to the criteria adopted in this paper. The aerosol monitored on these days was considered due to mixed source regions (Sector M).

Air masses from Sector A have the common property to travel across several urban and industrialized European areas before reaching Lecce. As a consequence, it was shown that Sector A air masses could be considered responsible for the transport of urban/industrial and biomass burning aerosols. In particular, the comparison of the Sector A aerosol parameter mean values $(\mathrm{AOD}=0.29 \pm 0.15, \eta=0.93 \pm 0.03$, $\mathrm{SSA}=0.93 \pm 0.03, g=0.67 \pm 0.03$, and $L r=72 \pm 20 \mathrm{sr}$ ) with previous investigations revealed that a "continental average aerosol", mostly made of water soluble and a small amount of soot and insoluble component was advected over southeast Italy from Sector A source regions. The analysis of the Sector B aerosol parameters, which were characterized by $\mathrm{AOD}=0.29 \pm 0.05, \eta=0.72 \pm 0.05$, SSA $=0.94 \pm 0.03$, $g=0.69 \pm 0.02$, and $L r=56 \pm 13 \mathrm{sr}$, revealed that desert dust particles advected over south-east Italy were also affected by the contribution of moderately-absorbing, fine-mode particles as those due to water soluble species: the predominant component of the "continental average aerosol" that is advected over the Mediterranean basin by the European continent. Hence, it was shown that polluted-desert dust particles were advected over south east Italy from Sector B source regions. It was also found that Sector $\mathrm{C}$ air masses were responsible for the advection over south-east Italy of 
maritime-polluted aerosol due to marine and to lesser extent anthropogenic particles from the Atlantic Ocean and/or the Western Mediterranean regions crossed by the Sector $\mathrm{C}$ air masses before reaching Lecce. Sector $\mathrm{C}$ aerosol parameter mean values (AOD $=0.27 \pm 0.17, \quad \eta=0.8 \pm 0.1$, $\mathrm{SSA}=0.94 \pm 0.03, g=0.67 \pm 0.03$, and $L r=58 \pm 24 \mathrm{sr}$ ) were compared to the values reported by previous studies to reach the above mentioned conclusion.

Table 2 revealed that 289 data points were ascribed to well defined source Sectors, In particular, $88 \%$ of the 289 measurement data were representative of "continental average aerosol" advected from Sector A source regions, while 6\% of measurement data were representative of polluted desertdust aerosol advected from Sector B source regions and of maritime-polluted aerosol advected from Sector C source regions, respectively. Hence, that the aerosol load over south-east Italy, in the central Mediterranean is dominated by "continental average aerosol" mostly made of moderatelyabsorbing, fine-mode particles even if it is also affected by the minor contribution of desert and maritime type aerosol. The results obtained by the application of an aerosol mask to the data points of Sector M, further more supported last comment. In accordance with the aerosol mask criteria it was found that $80 \%$ of the 369 Sector $M$ data points were representative of "continental average aerosol", while $14 \%$ and $6 \%$ of the data points were representative of maritime and desert-dust aerosol, respectively.

The geographical location of south-east Italy that is rather close to continental European regions is considered responsible of the predominant contribution of the "continental average aerosol" to the aerosol load of south-east Italy. Maritimepolluted and desert dust-polluted particles were also advected over south-east Italy from Sector C and B air masses, respectively. As a consequence, variability ranges and means values of the investigated aerosol parameters did not significantly vary from Sector to Sector with few exceptions. In particular, we found that $\eta$ and $L r$ average values were quite affected by the air mass source Sector, while AOD, SSA and $g$ average values were not significantly dependent on air mass source Sector. Finally, the comparison between the results of this paper with those retrieved at Lampedusa and Crete, reveled that the contribution of continental type aerosol made of fine-mode moderately absorbing particles reduces for Mediterranean coastal sites away from the European continent. In fact, it was shown that at Crete in the center of the eastern Mediterranean basin, continental urban/industrial and biomass burning aerosols were responsible of AODs lower than $\sim 0.2$. In contrast, the coarse-mode aerosols mostly due to natural sources dominated the total columnar volume of particles during all seasons except for summer, when they were of equal importance to fine particles. Hence, we believe that the mean properties of the southeast Italy aerosol load can be considered representative of most Mediterranean coastal sites rather close to the European continent and away from large sources of local pollution.
In conclusion, the results of this paper beside revealing that the aerosol characterization over the Mediterranean is complicated by the fact that a large number of sources and hence of aerosol species contribute to it, have contributed to the aerosol characterization over the Mediterranean, providing valuable data for future studies devoted to the evaluation of the direct radiative forcing by aerosols for this region.

Acknowledgements. This work was supported by Ministero dell' Istruzione dell'Università e della Ricerca of Italy, (Programma di Ricerca di Interesse Nazionale 2006. Prot. 2006027825), by the European Project EARLINET-ASOS (2006 -2010, contract n. 025991), by Progetto FIRS AEROCLOUDS and by Centro EuroMediterraneo per i Cambiamenti Climatici (CMCC).

Edited by: N. Mihalopoulos

\section{References}

Ackerman, J.: The extinction-to-backscatter ratio of tropospheric aerosol: A numerical study, J. Atmos. Oceanic. Technol., 15, 1043-1050, 1998.

Amiridis, V., Balis, D. S., Kazadzis, S., Bais, A., Giannakaki, E., Papayannis, A., and Zerefos, C.: Four-year aerosol observations with Raman lidar at Thessaloniki, Greece, in the framework of EARLINET, J. Geophys. Res., 110, D21203, doi:10.1029/2005JD006190, 2005.

Balis, D. S., Amiridis, V., Zerefos, C., Gerasopoulos, E., Andreae, M. Zanis, P., Kazantzidis, S., and Papayannis, A.: Raman lidar and sunphotometric measurements of aerosol optical properties over Thessaloniki, Greece during a biomass burning episode, Atmos. Environ., 37, 4529-4538, 2003.

Balis, D. S., Amiridis, V., Nickovic, S., Papayannis, A., and Zerefos, C.: Optical properties of Sahara dust layers as detected by a Raman lidar at Thessaloniki, Greece, Geophys. Res. Lett., 31, L13104, doi:10.1029/2004GL019881, 2004.

Barnaba, F. and Gobbi, G. P.: Aerosol seasonal variability over the Mediterranean region and relative impact of maritime, continental and Saharan dust particles over the basin from MODIS data in the year 2001, Atmos. Chem. Phys., 4, 2367-2391, 2004, http://www.atmos-chem-phys.net/4/2367/2004/.

Barnaba, F., Tafuro, A. M., De Tomasi, F., and Perrone M.R.: Observed and simulated vertically resolved optical properties of continental aerosols over southeastern Italy: A closure study, J.Geophys. Res., 112, D10203, doi:10.1029/2006JD007926, 2007.

Bellantone, V., Carofalo, I., De Tomasi, F., Perrone, M. R., Santese, M., Tafuro, A. M., and Turnone, A.: In situ samplings and remote sensing measurements to characterize aerosol properties over south-east Italy, in press by J. Atmos. Sci., 2008.

Cattral, C., Reagan, J., Thome, K., and Dubovik, O.: Variability of aerosol and spectral lidar and backscatter and extinction ratios of key aerosol types derived from selected Aerosol Robotic Network locations, J. Geophys. Res., 110, D10SA11, doi:10.1029/2004JD005124, 2005.

Charlson, R. J., Langner, J., Rodhe, H., Leovy, C. B., and Warren, S. G.: Perturbation of the northern hemispheric radiative balance 
by backscattering from anthropogenic surface aerosols, Tellus, 4AB, 152-163, 1991.

D'Almeida, G. A.: Atmospheric aerosols: global climatology and radiative characteristics, A Deepak Publishing, 1991.

De Tomasi, F., Blanco, A., and Perrone, M. R.: Raman lidar monitoring of extinction and backscattering of África dust layers and dust characterization, Appl. Opt., 42, 1699-1709, 2003.

De Tomasi, F., Tafuro, A. M., and Perrone, M. R: Height and seasonal dependence of aerosol optical properties over south-east Italy, J. Geophys. Res., 111, D10203, doi:10.1029/2005JD006779, 2006.

Dubovik, O. and. King, M. D.: A flexible inversion algorithm for retrieval of aerosol optical properties from Sun and sky radiance measurements, J. Geophys. Res., 105, 20 673-20 696, 2000.

Dubovik, O., Smirnov, A., Holben, B. N., King, M. D., Kaufman, Y. J., Eck, T. F., and Slutsker, I.: Accuracy assessments of aerosol optical properties retrieved from AERONET sun and sky-radiance measurements, J. Geophys. Res., 105, 9791-9806, 2000

Dubovik, O., Holben, B. N., Lapyonok, T., Sinyk, A., Mishechenko, M. I., Yang, P., and Slutsker, I.: Non-spherical aerosol retrieval method employing light scattering by spheroids, J. Geophys. Res. Lett., 29, 54-1-54-4, 2002.

Dubovik, O., Sinyuk, A., Lapyonok, T., Holben, B. N., Mishchenko, M., Yang, P., Eck, T. F., Volten, H., Munoz, O., Veihelmann, B., van der Zande, W. J., Leon, J-F, Sorokin, M., and Slutsker, I.: Application of spheroid models to account for aerosol particle nonsphericity in remote sensing of desert dust., J. Geophys. Res., 111, D11208, doi:10.1029/2005JD006619, 2006.

Duncan, B. N. and Bey I.: A modelling study of the export pathways of pollution from Europe : seasonal and interannual variation (1987-1997), J. Geophys. Res., 109, D08301, doi:10.1029/2003JD004079, 2004.

Formenti, P., Andreae, M. O., Andreae, T.W., Galani, E., Vasaras, A., Zerefos, C., Amidiris, V., Orlovsky, L., Karnieli, A., Wendisch, M., Wex, H., Holben, B. N., Maenhaut, W., and Lelieveld, J.: Aerosol optical properties and large scale transport of air masses : Observations at a coastal and a seniarid site in the eastern Mediterranean during summer 1998, J. Geophys. Res., 106, 9807-9826, 2001.

Formenti, P., Reiner, O., Sprung, D., Andreae, M.O., Wendisch, M., Wex, H., Kindred, D., Dewey, K., Kent, J., Tzortziou, M., vasaras, A., and Zerefos, C.: The STAARTE-MED 1998 summer airborne measurements over the Aegean Sea :1. Arosol particles and trace gases, J. Geophys. Res., 107, 4450, doi:10.1029/2001JD001337, 2002.

Fotiadi, A., Hatzianastassiou, N., Drakakis, E., Matsoukas, C., Pavlakis, K. G., Hatzidimitriou, D., Gerasopoulos, E., Mihalopoulos N., and Vardavas I.: Aerosol physical and optical properties in the eastern Mediterranean Basin, Crete, from Aerosol Robotic Network data, Atmos. Chem. Phys., 6, 5399_ 5413, 2006, http://www.atmos-chem-phys.net/6/5399/2006/.

Gerasopoulos, E., Andreae, M. O., Zerefos, C., Andreae, T. W., Balis, D., Formenti, P., Merlet, P. Amiridis, V., and Papastefanou, C.: Climatological aspects of aerosol optical properties in Nothern Greece, Atmos. Chem. Phys., 3, 2025-2041, 2003 , http://www.atmos-chem-phys.net/3/2025/2003/.

Gerasopoulos, E., Kouvarakis, G., Vrekoussis, M., Kanakidou, M., and Mihalopoulos, N.: Ozone varability in the marine boundary layer of the Eastern Mediterranean based on 7-year observations, J. Geophys. Res., 110, D15309, doi:10.1029/2005 JD005991, 2005.

Giorgi, F., Bi, X. Q., and Qian, Y.: Direct radiative forcing and regional climatic effects of anthropogenic aerosols over East Asia: A regional coupled climate-chemistry/aerosol model study, J. Geophys. Res., 107(D20), 4439, 2002.

Giorgi, F.: Climate change hot-spots, J. Geophys. Res., 33, L08707, doi:10.1029/2006GL025734, 2006.

Hatzianastassiou, N., Katsoulis, B., and Vardavas, I.: Global distribution of aerosol direct radiative forcing in the ultraviolet and visible arising under clear skies, Tellus, 56B, 4679-4690, 2004.

Hess, M., Koepke, P., and Schult, I.: Optical Properties of Aerosols and Clouds: The software package OPAC, B. Am. Meteorol. Soc., 79, 831-844, 1998.

Holben, B. N., Eck, T. F., Slutsker, I., Tanre, D., Buis, J. P., Setzer, A., Vermote, E., Reagan, J. A, Kaufman, Y., Nakajima, T., Lavenu, F., Jankowiak, I., and Smirnov, A.: AERONET - A federated instrument network and data archive for aerosol characterization, Rem. Sens. Environ., 66, 1-16, 1998.

Holben, B. N., Tanre, D., Smirnov, A., Eck, T. F., Slutsker, I., Abuhassan, N., Newcomb, W. W., Schafer, J., Chatenet, B., Lavenue, F., Kaufman, Y. J., Vande Castle, J., Setzer, A., Markham, B., Clark, D., Frouin, R., Halthore, R., Karnieli, A., O'Neill, N.T., Pietras, C., Pinker, R.T., Voss, K. and Zibordi, G.: An emerging ground-based aerosol climatology: Aerosol Optical Depth from AERONET, J. Geophys. Res., 106, 12 067-12 097 , 2001.

Horvath, H., Alados Arboledas, L., Olmo F. J., et al.: Optical characteristics of the aerosol in Spain and Austria and its effect on radiative forcing, J. Geophys. Res., 107(D19), 4386, 2002.

Kalkstein, L. S., Tan, G., and Skindlov, J. A.: An evaluation of three clustering procedures for use in synoptic climatological classification, J. Climate Appl. Meteor., 26, 717-730, 1987.

Kaufman, Y. J., Smirnov, A., Holben, B. N., and Dubovik, O.: Baseline maritime aerosol: methodology to derive the optical thickness and scattering properties, J. Geophys. res. Lett., 28, 17, 3251-3254, 2001

Kazadzis, S., Bais, A., Amidiris, V., Balis, D., Meleti, C., Kouremeti, N., Zerefos, C. S., Rapsomanikis, S., Petrakakis, M., Kelesis, A., Tzoumaka, P., and Kelektsoglou, K.: Nine years of UV aerosol optical depth measurements at Thessaloniki, Greece, Atmos. Chem. Phys., 7, 2091-2101, 2007, http://www.atmos-chem-phys.net/7/2091/2007/.

Lelieveld, J., Berresheim, H., Borrmann, S., et al.: Global air pollution crossroads over the Mediterranean, Science, 298, 794-799, 2002.

Lyamani, H., Olmo, F. J., and Alados-Arboledas, L.: Long-term change in aerosol radiative properties at Armilla, Atmospheric Environment, 38, 5935-5943, 2004.

Meloni, D., Di Sarra, A., Di Iorio T., and Fiocco, G.: Influence of the vertical profile of Saharan dust on the visible direct radiative forcing, J. Quant. Spectrosc. Radiat. Transfer, 93, 347-413, 2005.

Mihalopoulos, N., Stephanou E., Kanakidou, M., Pilitsidis, S., and Bousquet, P.: Tropospheric aerosol ionic composition in the eastern Mediterranean region, Tellus B, 49, 314-326, 1997.

Mishchenko, M. I., Geogdzhayev, I. V., Liu, L., Ogren, J. A., 
Lacis, A. A., Rossow, W. B., Hovenier, J. W., Volten, H., and Muñz, O.: Aerosol retrievals from AVHRR radiances: Effects of particle nonsphericity and absorption and an updated longterm global climatology of aerosol properties, J. Quant. Spectrosc. Radiat. Transfer, 79/80, 953-972, 2003.

Moody, J. L.: The influence of meteorology on precipitation chemistry at selected sites in the Eastern United States. Ph. D. dissertation, University of Michigan, Ann. Arbor., 176 pp.,1986.

Moody, J. L. and Galloway, J.N.: Quantifying the relationship between atmospheric transport at two sites in the midwestern United States, Atmos. Environ., 23, 2117-2132, 1988.

Muller, D., Mattis, I., Wandinger, U., Ansmann, A., Althausen, D., Dubovik, O., Eckhardt, S., and Stohl, A.: Saharan dust over a central European EARLINET-AERONET site : Combined observations with Raman lidar and Sun photometer, J.Geophys.Res., 108(D12), 4345, doi:10.1029/2002JD002918, 2003.

Pace, G., di Sarra, A., Meloni, D., Piacentino, S., and Chamard, P.: Aerosol optical properties at Lampedusa (central Mediterranean) 1. Influence of transport and identification of different aerosol types, Atmos. Chem. Phys., 6, 697-713, 2006, http://www.atmos-chem-phys.net/6/697/2006/.

Papayannis, A. Balis, D., Bais, A., van der Bergh, H., Calpini, B., Durieux, E., Fiorani, L., Jaquet, L., Ziomas, I., and Zerefos, C. S.: The role of urban and suburban aerosols on solar UV radiation over Athens, Greece, Atmos. Environ., 21, 2193-2201, 1998.

Papayannis, A., Balis, D. Amidiris, V., Chourdakis, G., Tsaknakis, G., Zerefos, C., Castanho, A. D. A., Nickovic, S., Kadzadzis, S., and Grabowsky, J. : Measurements of Saharan dust aerosols over the Eastern Mediterranean using elastic backscatter-Raman lidar, spectrophotometric and satellite observations in the frame of the EARLINET project, Atmos. Chem. Phys., 5, 2065-2079, 2005, http://www.atmos-chem-phys.net/5/2065/2005/.
Perrone, M. R., Santese, M., Tafuro, A. M., Holben, B., and Smirnov, A.: Aerosol load characterization over South-East Italy for one year of AERONET sun-photometer measurements, Atmos. Res., 75, 111-133, 2005.

Remer, L. A. and Kaufman, Y. J.: Dynamic aerosol model: Urban/Industrial aerosol., J. Geophys. Res., 103, 13 859-13 871, 1998.

Smirnov, A., Holben, B. N., Eck, T. F., Dubovik, O., and Slusker, I.: Cloud-screening and quality control algorithms for AERONET database, Remote Sens. Environ., 73, 337-349, 2000.

Smirnov, A., Holben, B. N., Kaufman, Y. J., Dubovik, O., Eck, T. F., Slutsker, I., Pietras, C., and Halthore, R. N.: Optical properties of atmospheric aerosol in maritime environments, J. Atmos. Sci., 59, 501-523, 2002.

Smirnov, A., Holben, B. N., Dubovik, O., Frouin, R., Eck, T. F., and Slutsker, I: Maritime component in aerosol optical models derived from Aerosol Robotic Network data, J. Geophys. Res., 108(D1), 4033, doi:10.1029/2002JD002701, 2003.

Stohl, A., Eckhardt, S., Forster, C., James, P., and Spichtinger, N.: On the pathways and timescales of intercontinental air pollution transport, J. geophys. Res., 107(D23), 4684, doi :10.1029/2001JD001396, 2002.

Tafuro, A. M., Barnaba, F., De Tomasi, F., Perrone, M. R., and Gobbi, G. P.: Saharan dust particle properties over the central Mediterranean, Atmos. Res., 81, 67-93, 2006. 